\title{
Barriers and Facilitators in Interorganizational Disaster Response: Identifying Examples Across Europe
}

\author{
Claudia Berchtold $^{1} \cdot$ Maike Vollmer $^{1} \cdot$ Philip Sendrowski $^{1} \cdot$ Florian Neisser $^{1} \cdot$ \\ ${\text { Larissa } \text { Müller }^{1} \cdot \text { Sonja Grigoleit }}^{1}$
}

Published online: 17 February 2020

(C) The Author(s) 2020

\begin{abstract}
Disaster response actors are facing new challenges, which encompass not only new and ever more complex threats but also the need to collaborate across organizational boundaries and even state borders. Depending on scale, these interactions have to work across governance setups, political and legal conditions, organizational cultures, as well as personal preferences and experiences that vary among actors, organizations, and countries. But which concrete measures are taken by crisis management actors at different scales to bridge these challenges and which of these could serve others as example to address comparable challenges in their contexts? This study made attempts to analyze whether certain solutions across organizations and states exist that facilitate effective interorganizational crisis management in the member states of the European Union (EU). It is based on selected expert interviews with representatives of different types of disaster response organizations (health services, police services, fire services, and other crisis management organizations) from seven EU member states (Germany, Netherlands, United Kingdom, Ireland, Italy, Austria, and Greece).
\end{abstract}

Keywords Disaster response · European union - Interorganizational crisis management $\cdot$ Transboundary cooperation

Claudia Berchtold

claudia.berchtold@int.fraunhofer.de

1 Department for Technology Analysis and Strategic Planning (TASP), Fraunhofer Institute for Technological Trend Analysis, 53879 Euskirchen, Germany

\section{Introduction}

Disaster response has become increasingly complex in recent years. While technological development and coordination efforts have added new opportunities to successfully manage complex crises, response settings are also gaining complexity, for example, in light of climate change and the resulting more intense natural hazards, or other threats such as terrorist attacks. Events such as the Manchester terrorist attack 2017, or the extreme wildfires of 2017, 2018, and 2019 demonstrate that collaboration requirements not only relate to cross-organizational settings within one state but may also require the deployment of resources across the member states of the European Union (EU).

Many actors operate efficiently with respect to the specific tasks their organizations have to fulfill. But when collaboration with other organizations or even jurisdictions is required, coordination efforts can pose a special challenge to effective disaster response (Boin and Bynander 2015). Respective challenges have repeatedly been reported. They usually arise from "problems with respect to: the communication process and information flow; the exercise of authority and decision-making; and, the development of coordination and loosening the command structure" (Quarantelli 1988, p. 375). Crisis management systems that involve different levels of decision making, where lower levels are dependent on higher levels, are seen as especially vulnerable to such coordination challenges (Sapountzaki et al. 2011).

In the 2011 explosion of confiscated arms-related material on the Cyprus naval base Mari, for example, early preventive action was stopped in its tracks by decision makers unfamiliar with the actual situation (Constantinides 2013). In another example, Portugal's wildfire suppression 
has in the past suffered from a lack of coordinated response, especially with respect to ensuring that fires were actually extinguished-when firefighters assumed the fire was extinguished they moved on, but no other organization on the ground was assigned the task to verify this, leading to the restarting of fires (Beighley and Hyde 2018).

While these are two examples relating to the national level, most recent activations of the European Union Civil Protection Mechanism (UCPM), for example during the wildfires in Sweden in 2018, have shown that these challenges are stretched beyond the nation state by the need of foreign assets to operate in new environments. For example, over 360 firefighting personnel, 7 planes, 6 helicopters, and almost 70 vehicles were deployed from across Europe to support the firefighting of wildfires in Sweden in 2018 (COMM/DG/UNIT 2018).

While the European level is an additional and essential layer of support in major crisis, it also adds new challenges in operating resources (modules) in foreign environments such as Southern European modules being deployed to Sweden. Addressing crisis management aspects at European level requires not only the consideration of different legal and governance frameworks and languages, but also the consideration of strategic, operational, and technical specificities that differ between countries. Nevertheless and in line with the increasing need to address respective aspects, civil protection activities are increasing at the European level. In March 2019, Decision (EU) 2019/420 amended Decision No 1313/2013/EU on a Union Civil Protection Mechanism (UCPM) ${ }^{1}$ and introduced additional response capacities as a last resort, where existing capacities at the national level and those pre-committed by member states are not able to ensure an effective response (rescEU) (for example Art. 12). The decision also constitutes the basis for the creation of a Union Civil Protection Knowledge Network (Art. 13) to strengthen the efficiency and effectiveness of civil protection training and exercises, to promote innovation and dialogue, and to enhance cooperation between the member states' national civil protection authorities and services. The legislation responds to 126 UCPM activations from participating states between 2002 and 2018 (EC-DG ECHO 2019a) with particularly devastating effects of the wildfires in 2017 and 2018. In Portugal, more than 120 persons lost their lives in the 2017 wildfire season (Turco et al. 2019). In Sweden, 74 fires burnt 21,605 ha, which is the second highest figure ever recorded in the EU (COMM/DG/UNIT 2019). In both cases, the UCPM was activated and support was granted from other EU countries.

\footnotetext{
1 The respective legislative document can be found at: https://eur-lex. europa.eu/legal-content/EN/TXT/?uri=CELEX\%3A32019D0420.
}

While there was general satisfaction with the ability of the UCPM to respond to disasters within the EU, at the same time, challenges were reported, for example in relation to National Contact Point (NCP) staff who did not speak English at the level of fluency required for facilitating a rapid response or with respect to the appropriateness of dispatched experts (EC-DG ECHO 2017). The challenges that language barriers and differences in equipment and command structures add to the deployment of experts in another state additionally have to be taken into account.

These insights are not new and are addressed at the European level by measures such as the UCPM training ${ }^{2}$ or exchange of experts program (EC-DG ECHO 2019b) to improve collaboration. In addition, civil protection aspects are also addressed bilaterally between member states in the context of cross-border collaborations and exercises. While these activities are very valuable to become acquainted with each other and to address more frequent events, particularly in boarder zones, the UCPM activation by Sweden during the 2018 wildfires requesting help from Southern Europe has shown that the support during crisis is no longer geographically limited. Hence, it needs to be discussed how respective interorganizational response challenges can be addressed at the European level. Is it possible to develop support structures that can facilitate the collaboration of member states and very special conditions such as the deployment of resources in member states that differ a lot from the dispatching country? If so, what are examples at the nation state level that might be of interest for the development of respective structures? And what can member states learn from each other to enhance the national interorganizational response? Measures taken at the local or national level might not only serve as an interesting example to enhance interorganizational collaboration at the European level but also for the member states as primarily responsible civil protection actors. Hence, the main question for this study was: can we identify practical examples of procedural or technological measures enhancing interorganizational response that could build a basis for further analysis? The explorative approach builds on 12 semistructured expert interviews that were conducted across the EU. These experts represented a range of geographical contexts and civil protection agencies, ranging from health services to firefighting organizations and the police. In these semistructured interviews, they were asked to identify facilitating and hindering aspects in interorganizational collaboration.

This article is structured as follows: after specifying the context of the analysis, the methodology of the research is

\footnotetext{
${ }^{2}$ For example: https://ec.europa.eu/echo/what/civil-protection/ experts-training-and-exchange_en.
} 
described. The subsequent analysis part is differentiated into two sections, namely technological and procedural aspects of interorganizational collaboration. It is followed by a discussion section and a conclusion section. Overall, the findings presented in this article provide insights on measures taken at the local and national levels to enhance interorganizational collaboration, which may serve as examples for other EU member states and could support the development of the way forward in European interorganizational disaster response.

\section{Contextualizing Interorganizational Disaster Response Challenges}

In the context of interorganizational disaster response it is important to differentiate settings and scales. For example, in the political sciences research, an important part of research has dealt with crisis and-with relevance to this article-aspects of transboundary crisis. Transboundary, in this context, means an event involving actors from more than one country or administrative region within one country. A crisis is traditionally defined as a shared perception of threat to a fundamental part or value of a society, which requires urgent action by authorities under conditions of deep uncertainty (Rosenthal et al. 1989). In that sense Boin (2019) refers to the 2008 economic crisis, the paralysis of air traffic in 2010 caused by the eruption of the volcano on Iceland (Eyjafjallajökull), and the 2015 "immigrant crisis" where hundred thousands of migrants entered Europe. Against this background, crisis management can be defined as "the set of preparatory and response activities aimed at the containment of the threat and its consequences" (Ansell and Boin 2019, p. 1082). Crisis management capacities, for example, at the European level are hence discussed in light of external border management capacities or the (lack of) capacities to respond to the financial crisis, frequently at a strategic policy level (Boin et al. 2014).

In contrast to this, disaster is defined, for example, as "serious disruption of the functioning of a community or a society involving widespread human, material, economic or environmental losses and impacts, which exceeds the ability of the affected community or society to cope using its own resources" (UNISDR 2009, p. 9). In this context, disaster risk management is "[...] the systematic process of using administrative directives, organizations, and operational skills and capacities to implement strategies, policies and improved coping capacities in order to lessen the adverse impacts of hazards and the possibility of disaster" (UNISDR 2009, p. 10). "These hazards may be of natural origin and related environmental and technological hazards and risks" (UNISDR 2009, p. 17). Comprehensive approaches to reducing disaster risk have been developed in the last decades and involve systematic efforts to analyze and manage the causal factors of disasters, including the reduction of exposure to hazards, lessened vulnerability of people and property, management of land and the environment, and improved preparedness for adverse events (UNISDR 2009). Respective procedures and practices are well established in many member states within the European Union and are facilitated - among others-by guidelines developed by the European Commission, on assessing risk (European Commission 2010) or risk management capability (European Commission 2015). Activities in managing risk are usually structured around four phasesprevention, preparedness, response, and recovery-with main actors being involved in response activities encompassing first responder organizations such as firefighters or health services. They ensure the provision of emergency services and public assistance during or immediately after a disaster in order to save lives, reduce health impacts, ensure public safety and meet the basic subsistence needs of the people affected.

Overall, the concepts of (transboundary) crisis (management) and disaster (response) can be differentiated along three main dimensions: materialization of impact, actors involved, and relevant hazards or threats (Table 1).

This article focuses on disaster response. It addresses questions of interorganizational disaster response, a field in the civil protection domain that is more institutionalized than crisis management (Boin et al. 2014). In this sense, actors involved in disaster response, particularly at a local level, collaborate and know each other. At a higher level, for example, when it comes to larger-scale multi-actor settings, potentially even crossing state borders, operations can be challenged by matters of interoperability. For example, the EFRIM (European First Responder Innovation Managers) platform has identified five dimensions of interoperability, namely governance, standard operating procedures (SOPs), technology, training \& exercises, and usage. ${ }^{3}$ But what are facilitators and barriers to actually creating and enhancing collaboration between organizations and services in these dimensions? Following this research question, the aim of the work conducted was to get an initial idea of why collaboration is particularly distinct in certain countries while they are not in others.

\footnotetext{
3 The "Interoperabilty Continuum" can be found on the EFRIM website: https://efrim.org/.
} 
Table 1 Differentiation of crisis management and disaster response

\begin{tabular}{|c|c|c|}
\hline & Crisis (management) & Disaster (response) \\
\hline $\begin{array}{l}\text { Materialization } \\
\text { of impact }\end{array}$ & $\begin{array}{l}\text { High level of uncertainty, impacts not yet materialized or } \\
\text { only to a limited extent. The management of the crisis } \\
\text { occurs during an ongoing process of varying extent. }\end{array}$ & $\begin{array}{l}\text { Impact materialized as results of a hazard, be it natural or } \\
\text { man-made. The response occurs in the aftermath of the } \\
\text { disaster. }\end{array}$ \\
\hline Actors involved & $\begin{array}{l}\text { Policymakers and executing/administering authorities trying } \\
\text { to delimit or prevent the impact. }\end{array}$ & First responder organizations and affected authorities. \\
\hline $\begin{array}{l}\text { Relevant } \\
\text { hazard or } \\
\text { threat }\end{array}$ & $\begin{array}{l}\text { Range of threats with perceived negative impacts on society } \\
\text { including, for example, financial crisis, "immigration } \\
\text { crisis", or volcano eruption. }\end{array}$ & $\begin{array}{l}\text { Usually natural and man-made hazards encompassing } \\
\text { geological, meteorological, hydrological, oceanic, } \\
\text { biological, and technological sources, sometimes acting in } \\
\text { combination [Man-made (that is, anthropogenic, or human- } \\
\text { induced) hazards are defined as those "induced entirely or } \\
\text { predominantly by human activities and choices." This term } \\
\text { does not include the occurrence or risk of armed conflicts } \\
\text { and other situations of social instability or tension that are } \\
\text { subject to international humanitarian law and national } \\
\text { legislation. Technological hazards are normally considered } \\
\text { a subset of man-made hazards (UNISDR 2018, p. 13)]. }\end{array}$ \\
\hline
\end{tabular}

\section{Methodology}

The analysis was based on selected expert interviews. The overall goal of the study, the interview setup and theoretical background, as well as the selection of interview partners and the implementation of the interviews are detailed in this section.

\subsection{Goal of the Analysis}

In line with the presented research questions, we wanted to explore which means or factors tend to facilitate effective collaboration between organizations, with the aim to lay a basis for being able to derive concrete recommendations for policymakers and operational staff at a later stage. Respective means could encompass particular framework conditions as well as procedures or tools that are used. In that sense, this study was not aiming to provide a comprehensive list of all underlying factors that influence interorganizational collaboration in disaster response. Rather, this explorative qualitative study aimed to sketch some solutions that have enhanced (or constrained) interorganizational collaboration as a basis for further research. To derive an initial overview of these factors, we conducted exploratory expert interviews that aimed to identify aspects that facilitate interorganizational response. Expert interviews can be regarded as snapshots that reflect the analysis of state and process at the time of the investigation (Flick 2004).

For this study, mainly results of expert interviews that directly addressed measures to facilitate interorganizational disaster response have been used. They were complemented by results of expert interviews that have addressed factors hindering or supporting innovation processes in disaster management. The aim of combining both groups of interviews for this study was to capture besides direct measures, also factors that indirectly determine the success of such measures by influencing their implementation process.

\subsection{Theoretical Background}

In order to structure the research, the principal tasks that responder organizations have to fulfill were deducted from existing research first. This grouping aimed at structuring the tasks that response organizations have to fulfill individually and jointly and should cater for the variety of crisis management actors such as firefighting organizations, health services, and the police, and the tasks they have to fulfill. Functional approaches were developed for example by Stolk et al. (2012) in the context of the ACRIMAS project $^{4}$ as well as by Wybo and Kowalski (1998). Wybo and Kowalski differentiated four functions for command and control centers-perception, analysis, communication, and information. Stolk et al. (2012) developed a slightly broader approach and identified six tasks-coordination, command, and control; situation assessment; information management/distribution; monitoring/information gathering; supply of basic services to enable crisis management; and logistics.

Building on the above-mentioned works and further readings (Endsley 1995; Balcik and Beamon 2008;

\footnotetext{
${ }^{4}$ The ACRIMAS project (Aftermath Crisis Management System-ofSystems Demonstration Phase I, FP7) was concerned with the identification of critical areas and topics within EU Crisis Management $(\mathrm{CM})$.
} 
Table 2 Differentiation of disaster response tasks

\begin{tabular}{|c|c|}
\hline Disaster response task & Short description \\
\hline Situation assessment & $\begin{array}{l}\text { Understanding of the situation and development of an operational picture: The analysis of situation assessment as } \\
\text { a crisis management task encompasses the continuous data collection, processing and monitoring of } \\
\text { information from different sources. More precisely, it can be defined as "the perception of the elements in the } \\
\text { environment within a volume of time and space, the comprehension of their meaning, and the projection of } \\
\text { their status in the near future" (Endsley 1995, p. 36). }\end{array}$ \\
\hline Decision making & $\begin{array}{l}\text { Making of decisions based on the situation assessment and available resources, sometimes with the help of } \\
\text { dedicated systems and tools. In general, two main ways of decision making and information sharing can be } \\
\text { found in the literature. Coordination thereby describes a rather hierarchical chain of command and control } \\
\text { within crisis management. In contrast, cooperative ways of crisis management can be characterized as more } \\
\text { decentralized decision-making structures (Groenendaal et al. 2013). }\end{array}$ \\
\hline $\begin{array}{l}\text { Coordination, command, and } \\
\text { control }\end{array}$ & $\begin{array}{l}\text { Coordination, command, and control (C3) is a crisis management doctrine that is often used. How it is used is } \\
\text { partially determined by organizational structures and the management of information within and across } \\
\text { organizations. Many organizations are organized in a three-tiered hierarchical command structure, with } \\
\text { decisions being fed from strategic (responsible for setting overall objectives) to tactical (setting parameters and } \\
\text { level of autonomy for operational level to work to) and operational (managing the incident ground) level } \\
\text { (Waring et al. 2018). }\end{array}$ \\
\hline Logistics & $\begin{array}{l}\text { Logistics planning and management are organized and conducted and crisis resources are prepared, stored, and } \\
\text { provided when necessary. Logistics is designed primarily to meet the needs of the responders and affected } \\
\text { population, particularly in times of infrastructure breakdown. Challenges encompass, for example, the } \\
\text { following aspects: technical, in the sense that special equipment is needed; organizational, relating to the need } \\
\text { for special planning and preparedness activities; and logistical, since equipment and personnel need to be } \\
\text { deployed to the affected area (Balcik and Beamon 2008). }\end{array}$ \\
\hline $\begin{array}{l}\text { Communication with the } \\
\text { public }\end{array}$ & $\begin{array}{l}\text { Communication with the public by the means of different media including radio, television, newspapers, } \\
\text { wallpaper, Facebook, Twitter, and other channels that can be employed to transmit critically valuable } \\
\text { information to as many people as possible (Radisch et al. 2013). }\end{array}$ \\
\hline
\end{tabular}

Groenendaal et al. 2013; Radisch et al. 2013; Waring et al. 2018), five functions were selected as tasks that structured the interview design-situation assessment; decision making; coordination, command, and control; logistics; and communication with the public (Table 2).

\subsection{Interview Design}

All interviews were designed in a semistructured way, making use of interview guidelines. The guidelines were based on and deducted from the above-mentioned literature on disaster response tasks. In this way, it was intended to find answers to the particular response tasks under consideration while leaving sufficient room to the opinions, experiences, and judgements of the interviewee and to allow for the consideration of aspects that had not been considered beforehand. Questions for the guidelines were derived from the desk research conducted beforehand and targeted research gaps but also expert opinion on topics of interest according to the literature.

The guidelines for the first group of interviews, which directly addressed measures to enhance interorganizational disaster response, were designed according to the five functions and differentiated between (1) technologies employed by an organization and their respective strengths and weaknesses to fulfill the described tasks collaboratively; and (2) procedural and organizational good practices and failure factors in fulfilling these tasks. More concretely, it was asked:

- Which technologies are used in your organization for transboundary/interorganizational Situation Assessment/Decision Making/Coordination, Command, and Control/Logistics/Communication with the Public?

- What have been the strengths and weaknesses of the employed technologies?

- What are best practice procedures and hindering factors relating to transboundary/interorganizational response operations applied by your organization with respect to Situation Assessment/Decision Making/Coordination, Command, and Control/Logistics/Communication with the Public that might be of added value for other organizations?

An attribution of strengths and weaknesses, as well as good practices and failure factors, was based on the assessment of the interviewees who were asked to outline facilitating and hindering aspects in interorganizational crisis management.

The second group of interviews was related to innovation implementation processes. Questions included:

- From your point of view, which factors had an influence on the way or the velocity of the implementation [of an innovation]? 
- Summarizing the different influencing factors, how strong was the influence of each factor, from your point of view?

The interviewees were asked to explain each of the mentioned factors, which allowed deriving an understanding of the relevance and character of each factor.

\subsection{Selection of Interview Partners}

Following a qualitative social science research approach, a theoretical sampling of experts was conducted (Flick 2007; Mayring 2007; Robinson 2014). To get a comprehensive idea of enhancing and constraining factors in crisis and disaster response, a bandwidth of different characteristics (for example, different member states, different operational tasks and backgrounds) was incorporated in the explorative study. The sampling should represent a range of organizations active in disaster response and at the same time represent a large geographical area. Therefore, different types of organizations were taken into account: health services, police services, fire services, operational control centers, and crisis management organizations. In terms of geographical scope, countries from West/Central Europe (Germany, Netherlands, and Austria), Northern Europe (UK and Ireland), as well as from Southern Europe (Greece and Italy) were selected. Interview partners of the first group of interviews were representatives of organizations contributing to a research project on enhancing interorganizational crisis response. ${ }^{5}$ The interview partners of the second group have been intensely involved in innovation processes to improve the disaster response capabilities of responder organizations. Thus, the second group was anticipated to be highly valuable to cover aspects of innovation management and technical and nontechnical progress within organizations for crisis management and disaster response. Most participants worked at the tactical level in their organizations. ${ }^{6}$ Each of the interviews lasted

\footnotetext{
$\overline{5}$ The active participation of the organizations in the project can be interpreted as an increased willingness to improve interorganizational crisis response, based on their individual knowledge and experience regarding previous attempts and unresolved issues to improve the situation, or shortfalls that they have recognized but that could not yet be solved. At the same time, the participation might be the result of positive experiences and the wish to further enhance the level of interorganizational collaboration. Overall it has to be acknowledged that the selection is biased towards organizations that have an interest in the topic.

${ }^{6}$ Interviews have been conducted under consideration of the General Data Protection Regulation. A majority of the interviewees expressed in the informed consent forms the wish to not being mentioned individually. To avoid that individual statements can be traced back, only country and organization type are mentioned as references in the analyses.
}

between one and two hours. Table 3 presents an overview of the interviews conducted.

\subsection{Implementation and Analysis}

Interviews were scheduled in advance and the interview guideline was provided for the information of the interviewee. All interviews were conducted via telephone or audio conference based on the above detailed interview guidelines. All interviews were transcribed.

The content of the transcribed interviews was analyzed qualitatively (Mayring 2014). In an inductive process, statements were clustered to aspects that were mentioned to facilitate or hinder interorganizational response collaboration. The main factors are detailed below.

\section{Findings}

The first and surprising finding for us was that the deducted structure for analysis, that is, the disaster response tasks described in Sect. 3.2, did not play a role in the answers of the interviewees. Most of the time, they described relevant aspects that related to collaborative response in general. In line with the differentiation between technologies and procedures, several aspects that facilitate or hinder collaboration could be identified. According to this structure, two of the main findings are a limited level of exploiting opportunities of technologies in responding to crisis, and shortfalls in determining appropriate interorganizational procedures of collaboration.

The chosen classification illustrated in Fig. 1 is just one possible approach. The aspects selected for "Barriers" may also be "Facilitators" if reduced to a minimum, and vice versa. For example, if a shared vision exists, the barrier "Lack of shared vision" is nonexistent. Contrariwise, the shared vision can be regarded as facilitator. Barriers and facilitators for an appropriate use of technologies are also often very much related to procedural barriers or facilitators. For example, potential negative effects of information sharing can directly lead to the limited validity of the Common Operational Picture (COP), if crucial information is not shared, and are understood in that sense as procedural barriers. But they can also prevent organizations from using a technology at all, for example, if police services refrain from introducing a joint information sharing system because sensitive information could be revealed. Thus, the chosen categories are strongly interconnected.

\subsection{Technological Aspects}

The first aspect addressed by the interviews was the question of which technologies are employed by the 
Table 3 Overview on the interviews conducted

\begin{tabular}{llll}
\hline Interview No. & Country & Organization type & Research context \\
\hline 1 & Netherlands & Safety Region (1) & Research on measures to facilitate interorganizational response \\
2 & Italy & Firefighter & \\
3 & Greece & Regional Civil Protection Authority & \\
5 & Ireland & Health Service & \\
6 & UK & Police & Research on innovation factors in disaster management \\
7 & Germany & Police & \\
\hline 8 & Germany & Police & \\
9 & Netherlands & Organization supporting Safety Regions & \\
10 & Netherlands & Safety Region (2) & \\
11 & Netherlands & Safety Region (3) & \\
12 & Germany & Operational Control Center & \\
\hline
\end{tabular}
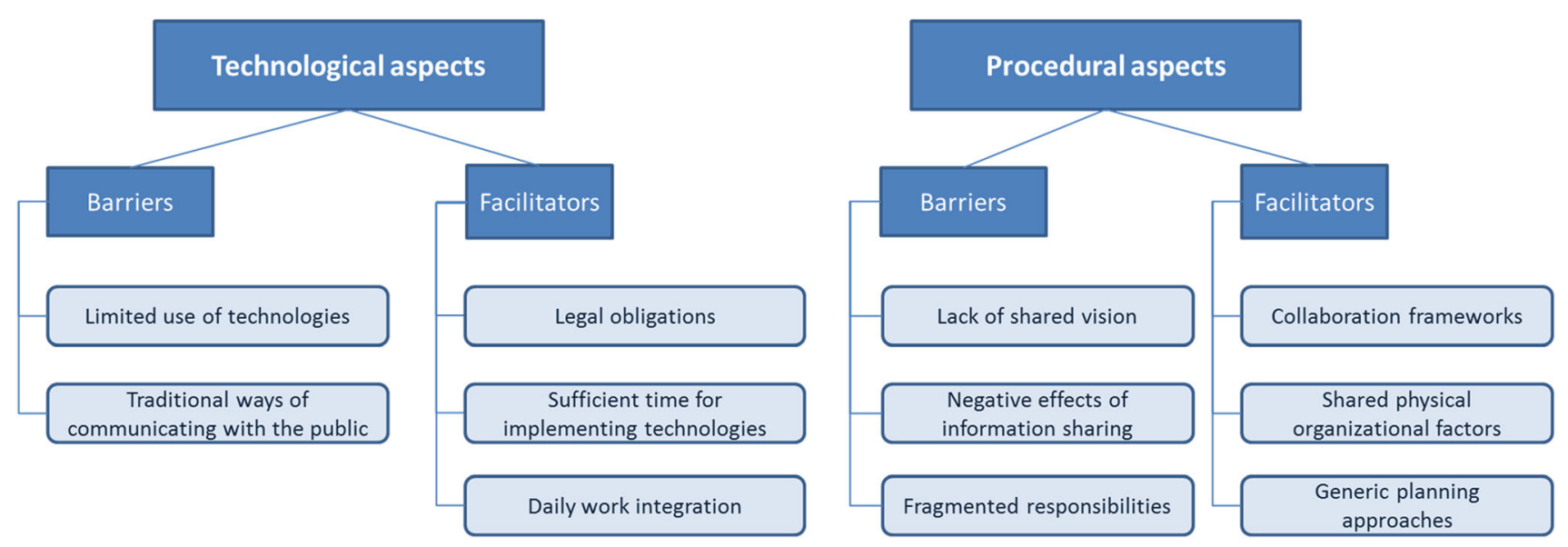

Fig. 1 Factors that constrain or facilitate interorganizational disaster response

organization under consideration, as well as their respective strengths and weaknesses in interorganizational response.

\subsubsection{Cooperation Barriers}

\section{(1) Limited use of technologies for situation assessment and information sharing}

A broad range of comparatively new situation assessment and information sharing technologies exists for managing the response to crisis. They include remote sensing technologies that can be used for rapid damage assessment, collaborative virtual working spaces to share information such as command and control systems or systems enabling multiple agencies to create a Common Operational Picture, and the use of Geo-Information Systems (GIS) and GPS signals to map the status quo. Generally, however, most of the interviewees stated that in practice they hardly used new information technologies, such as Command and Control systems or GIS, for information sharing. Instead, information frequently continues to be passed on orally (mostly by radio communication) or in written form including the use of emails from the field to the control centers. "The weakness of the current system is the impossibility to share information quickly over a larger number of partner organizations" one respondent (Interview No. 5) concluded, while another detailed that "all coordination during the emergency is organized via phone calls, emails and sometimes fax. Its automation could save essential time" (Interview No. 3). It has become clear that technology is often still used to facilitate the established direct peer-to-peer communication, written or orally, relying on already well established older technologies. The potential of using systems integrating a variety of users and 
information sources under a single roof, allowing information sharing, automated information flow, and multipartner communication is often neglected.

Some organizations make use of GPS systems to track staff and/or resources such as vehicles, which allows information from the field to be allocated more precisely to a geographic location and to keep an overview over deployed resources at the same time. Nevertheless, since they usually are isolated solutions only used by single organizations, they still "require manual translation of the common operational picture" (Interview No. 5). Control centers usually use some form of (electronic) blogs or logkeeping of information received and decisions taken. Most organizations translate the information received from the field into an electronic COP. In terms of sharing information across organizations, manual methods using pencil and paper or white board continue to be used by many organizations (Interviews No. 2-6). While this impedes the electronic and thus fast sharing of major amounts of information with other organizations, it also leads to difficulties in storing shared information in a prolonged crisis.

The use of technologies that include the integration of pictures would enhance the operational picture. Currently, due to the lack of (visualized) situation assessment tools, some emergency managers use social media reports and pictures to get an overview over the crisis situation. However, "their use is not [always] formalized" (Interviews No. 4 and 5). Consequently, "the most important failure factor is the time lag between receiving information and acting upon it due to the manual processes for the translation and sharing of information" [from these media] (Interviews No. 5 and 7). In addition to this shortfall at the organizational level, this time lag is repeated among the organizations involved, hence accumulating important time losses for one emergency. Efficiency gains by automating information management could be derived by making use of technologies across organizations. At the same time, it has to be taken into account that different and often noninteroperable technologies present a significant barrier to cooperation (Interviews No. 4-6).

The explanations for the limited use of information sharing technologies were manifold and ranged from a lack of funding to a lack of priorities and the unwillingness to share information, data protection and privacy regulations, and administrative hurdles. The latter can encompass, for example, fragmented responsibilities in terms of collecting data (Interview No. 2) but also regulatory burdens. For example, operational control centers and also other public organizations are subject to compulsory EU-wide tender processes, which can complicate and prolong procurement actions. In addition, once complex IT systems are ordered, it remains a challenge to bring together the supplier's expert knowledge on the technology with the user's knowledge on their specific needs (Interview No. 12). Finally, from a technical point of view it is challenging to integrate existing systems. An integrated operational control center in Germany, for example, has implemented compatible IT systems for the daily operational control and for disaster management. Using a single system, however, does not seem possible, since too many different organizations that all use their own systems can be involved in disaster management (Interview No. 11).

Apart from potentially fixable technical issues, introducing collaborative technology in addition to or to replace existing systems (legacy systems) poses its own organizational challenges. It would require many organizations' support and commitment at a higher management level or binding decisions/regulations at even higher level since organizations can have different priorities, or simply just not have the required money or resources; or, organizations had developed their own systems that they were used to, that were tailored to their specific needs, with their preferred data formats and so on. Giving up on an organization's own innovation that has also cost a lot of efforts, in favor of a new one coming from the outside, where the concerned organization has less influence, can require very good arguments, and trust (Interviews No. 8-10).

\section{(2) Traditional ways of communicating with the public}

Communicating with the public is a general challenge for individual organizations, some of which continue to focus the communication with the population on long-established ways such as transceivers that can be deployed to community leaders or direct communication via commanders. Radio, television, newspapers, and telephone calls remain important channels for social, cultural, and also technical reasons. This is particularly true since communicating with the public in crisis situations for warning, sourcing, and tasking purposes needs to take the persistent gap between those who are able to benefit from the Internet, and those who are not, into account. Furthermore, individuals might not be able to (re)charge their mobile phones, the connection might be disrupted, and it remains unclear whether individuals will be able to use phones properly during a disaster event due to the stress induced by the situation, smoke, and so on. In addition, the speed of social media challenges crisis management organizations. "This is specifically true, since crisis management organizations have to rely on people to share their messages to be effective and thus messages have to be up-to-date and relevant" (Interview No. 5). Therefore, "geo-referenced technologies are not applied" by some organizations (Interviews No. 2 and 4), but some organizations make use of specific warning apps that are employed by the public services and allow them to send messages to registered users (Interview No. 7). 
The challenges in using technologies for situation assessment and information sharing, in combination with the challenges in communicating with the public, can lead to difficulties in communicating coherently across organizational borders.

\subsubsection{Facilitators of Cooperation}

\section{(1) Legal frameworks}

A very good technical example for information management within and between organizations is a solution established in the Netherlands. It allows for the generation of an interorganizational Common Operational Pictures and exchange of information on response actions that are available (Interview No. 1). The Dutch information sharing and management platform (Landelijk Crisismanagement Systeem, LCMS) is used by all 25 safety regions in the Netherlands. ${ }^{7}$ It is used for training, as well as for operational purposes and different emergency services, and by different teams at all levels of command. It comprises different Geographic Information System (GIS) layers that contain information on critical objects (for example, schools, hospitals and so on) as well as an actual incident layer that is created from the field. One information manager in the field is responsible for updating this layer. Each organization has its own access to the system and takes its own actions, which are shared via LCMS. Photos, videos, as well as modeling results (for example, on flooding) can also be added to the system.

The 2010 Safety Regions Act (Dutch Ministry of Security and Justice 2013), which has been the basis for establishing the 25 Safety Regions in the Netherlands, also explicitly mentions requirements for improving information management. Thus, by explicitly requesting investments in information management, the law clearly encouraged the use of a joint system-the LCMS (Interview No. 8).

\section{(2) Sufficient time for implementing technologies}

The time period from the very first introduction of a new technology until it is really usable and provides clear benefits, as compared to the situation before, can be very long. In the case of the LCMS, the whole process, which included several projects (one for each Safety Region, with their different peculiarities), took about eight years until the system was really usable (Interviews No. 8 and 10).

\footnotetext{
7 The safety regions were established to improve disaster and crisis management in the Netherlands. The Safety Regions Act (2010) organizes the fire services, emergency medical assistance, and crisis management under one regional administrative authority to ensure efficient and high-quality disaster and crisis management (Dutch Ministry of Security and Justice 2013).
}

The issue of long implementation timelines has also been confirmed in interviews with experts involved in other technology implementation processes (Interviews No. 1, 4, 5). An original time plan can quickly be destroyed by resource issues, discussions on implementation details, or political incentives. In addition, time pressure can lead to stress and refrain from reporting problems-in contrast, allowing the necessary implementation time including time for testing and adaptation, can be a success factor (Interviews No. 11 and 12).

\section{(3) Daily work integration}

In order to make technology usable in crisis situations, it is crucial that it is either also used in non-crisis times, and/or is similar to other technologies that are used in daily work-such as a crisis management IT system that has a similar interface as commonly used software. In addition, regular training can fulfill this requirement (Interviews No. $8,11,12)$.

\subsection{Procedures}

The above findings show that new technologies can only unfold their potential if the contextual factors, such as legal basis or time for implementation, facilitate the implementation. They also help to explain why manual methods using pencil and paper or white board continue to be used. Against the frequently lacking use of higher-order technologies, it is even more important to understand aspects that can facilitate or constrain the procedures in collaborating.

\subsubsection{Cooperation Barriers}

\section{(1) Lack of shared vision and organizational differences}

Not having a shared vision and understanding on the aim to collaborate poses a significant barrier to interorganizational collaboration. Particularly the resistance to share information plays a role here. While the technical implementation of itself is quick and easy (the only requirements are Internet and a browser), the respective changes in the working processes involved take time. For example, implementing a new system of information management across different regions and across different types of organizations can require several changes far beyond the technical implementation. An example is the LCMS in the Netherlands, which is actually just the tool to support a new way of working together (the "net-centric" approach, see for example Boersma et al. 2012). Implementing collaboration in such a way and developing a common understanding of a need for being able to share information in a short time succeeded in the case of the LCMS. 
However, the actual willingness to share information was one of the hurdles, prolonging the implementation process (Interviews No. 8-10). Particularly organizational differences, such as norms and rules, hierarchies, working methods and terminologies, which create specific organizational cultures, were identified as one key issue for communication problems in collaboration (Interviews 1, 2, $5,7,8)$ that make the establishment of a shared vision more difficult.

\section{(2) Negative effects of sharing information}

The sharing of information in general requires compromises, for example between the advantage of having a very good level of information that enables quick and most useful decision making, and possible negative effects of sharing information that could be used in a wrong way. This concerns for example the police, but also private companies involved, such as critical infrastructure operators, who do not want to reveal certain types of information. Here, good communication, building trust, and agreements on what can be shared and what will not be shared, is crucial (Interviews No. 9 and 10). In addition, public organizations are subject to freedom of information laws, which force them to reveal information if requested by the media or the public. Some organizations fear that this information could be used against them, for example, if something did not work out in a desired way, and the information shared in a system is used to blame specific persons or organizations (Interview No. 10).

\section{(3) Fragmented responsibilities}

In federal countries, where disaster management is the responsibility of lower administrative levels, there is the advantage that disaster management can be organized tailored to the specific local needs. At the same time, the disadvantage is that systems have developed heterogeneously. It can easily happen that two communities are working on exactly the same problem, without knowing, using considerably more resources than if they had worked together. Thus, a good network and information exchange can avoid waste of money, but this is not always easy to put into practice (Interviews No. 11 and 12). Additionally, difficulties can arise when responsibilities need to be upscaled in the case of major emergencies and coordination is required over a range of services using different technologies and are based on various legal bases (in Germany, for example, crisis management is usually the responsibility of the 16 Länder $^{8}$ and consequently, 16 different civil protection laws exist within one country.

\footnotetext{
8 The respective responsibilities are determined by the German constitution (Art. $30 \mathrm{GG}$ together with Art $70 \mathrm{ff}$ GG, see also BMI (2015)).
}

\subsubsection{Facilitators of Cooperation}

\section{(1) Collaboration frameworks}

While efficiency is lost by not using information sharing technologies, collaboration between organizations still works particularly well when frameworks exist that establish and detail roles and processes. For example, the added value of the "Joint Doctrine: The interoperability framework (JESIP)" (Joint Emergency Services Interoperability Principles) (Chief Fire Officers Association, Association of Ambulance Chief Executives and National Police Chiefs' Council 2016) in the United Kingdom was clearly emphasized (Interview No. 5). In Ireland, the Framework for Major Emergency Management and its Annexes outline the interorganizational emergency management collaboration (National Steering Group Ireland 2017). Both frameworks define the national, regional, and local collaboration and facilitate the selection of a lead agency for multi-organizational settings. They furthermore define key roles in coordinating and simultaneously set parameters/boundaries for the mandate/authority given with the coordination responsibility (National Steering Group Ireland 2017).

\section{(2) Shared physical organizational structures}

An organizational example from Germany is the physical sharing of control centers. There is an integrated operational control center in Germany, which is responsible for three counties (Landkreise) in Lower-Saxony. This is an innovative development considering Germany's federal system, where control centers are usually operated on city or county level. In addition, a special collaboration between emergency rescue services, fire brigade, and police exists here: they are working together in the same building, sharing technology and logistics, while keeping clear boundaries of responsibilities (Interview No. 11).

\section{(3) Generic planning approaches}

Another interesting organizational approach that facilitates Command and Control (C2) processes, the asset registry, was mentioned by one respondent (Interview No. 5). This registry contains information on available resources and capabilities, giving an overview on their availability, including the training level of staff, for example for the use of certain equipment. With this approach, the planning shifts towards one general plan and a capability and resources-driven response built on a generic plan and procedure, and facilitates collaboration between organizations. 


\section{Discussion}

This article has presented technological and procedural factors that hinder and facilitate interorganizational collaboration as derived through 12 semistructured expert interviews. The seven European Union member states covered in this explorative study (Germany, Netherlands, United Kingdom, Ireland, Italy, Austria, and Greece) and their organizations (police, firefighting, crisis management, and health services) represented in the expert interviews cover a range of countries and different types of actors. Among these actors certain aspects were repeatedly mentioned and allowed for drawing preliminary commonalities on the barriers and facilitators in interorganizational response. At the same time, this first overview is based on a limited number of actors and countries and thus cannot be regarded as representative. While this needs to be clearly taken into account, the results present a starting point for further analysis on how to overcome the existing challenges.

In terms of the main findings (Table 4), it is notable that while the internet, mobile devices, and new technological developments have generated a large and diverse landscape of tools that could facilitate disaster response, managerial tasks in crisis management remain frequently based on oral (personal or radio) and email communication, as well as paper and pencil or white board note-taking. Even when these methods represent important fallback options, for example in case of a technology failure, the general lack of electronic information sharing leads to time lags in forwarding and updating information for deriving a shared $\mathrm{COP}$ and to challenges in storing information in case of a prolonged crisis. Furthermore, the overlay and combination of data and information are limited when using analog media or "traditional" approaches. This is true for the analysis of an ongoing operation, the management of a crisis or disaster, as well as for dissemination purposes. While the Netherlands have had a very good experience with the introduction of a national electronic information sharing platform, other countries do not only lack electronic supporting tools but (in certain cases) specifications for processes in interorganizational crisis management. In this respect, the United Kingdom and Ireland have experienced good interorganizational collaboration due to their existing frameworks that establish the procedural basis for interorganizational crisis collaboration. This could be a starting point for other states that want to enhance their interorganizational collaboration capability and may also be considered for enhancing the interoperability of responder organizations at EU level.

Overall, the lack of standardized collaboration procedures and the lack of digital information to facilitate a faster sharing of information with several organizations can be regarded as major challenges to interorganizational collaboration in disaster response. Specifically, the lack of electronic information was mentioned as a challenge by almost all interview partners. In order to overcome these shortfalls, it is useful to take a closer look at the reasons. Political and juridical barriers, such as data protection concerns, the lack of resources, as well as organizational and sociological factors, such as a lack of trust and personal contacts between organizations, are aspects that contribute to reluctance in sharing information and data. At the same time, moving from not having official collaboration frameworks for procedural structures to an electronic information and coordination system despite all these difficulties requires profound organizational change. This does not only relate to procedures and responsibilities but also to organizational culture (for example, in terms of willingness to share information) and a reflection about an organization's own organizational setup and weaknesses. Most importantly though, neither the development of collaboration frameworks nor the implementation of technologies will be successful without a shared vision and the clear commitment of decision makers to support such activities.

Table 4 Overview of the main findings on the barriers and facilitators in interorganizational disaster response (DR: Disaster response)

\begin{tabular}{|c|c|c|}
\hline & Main barriers & Main facilitators \\
\hline \multirow[t]{2}{*}{ Technological } & $\begin{array}{l}\text { Little use of electronic information sharing leading to prolonged } \\
\text { processes }\end{array}$ & Increasing number of supporting technologies for DR \\
\hline & $\begin{array}{l}\text { DR remains frequently based on oral (personal and radio) and e-mail } \\
\text { communication }\end{array}$ & $\begin{array}{l}\text { Availability of electronic information sharing } \\
\text { platforms }\end{array}$ \\
\hline \multirow[t]{3}{*}{ Procedural } & Little integration of existing technologies into workflow & $\begin{array}{l}\text { Existence of mutually agreed cooperation } \\
\text { frameworks }\end{array}$ \\
\hline & $\begin{array}{l}\text { Lack of standardized collaboration procedures for interorganizational } \\
\text { DR }\end{array}$ & $\begin{array}{l}\text { Shared visions regarding cooperation between DR } \\
\text { organizations }\end{array}$ \\
\hline & & $\begin{array}{l}\text { An organizational culture open to cooperation and } \\
\text { change }\end{array}$ \\
\hline
\end{tabular}




\section{Conclusion}

The identified barriers and facilitators in interorganizational disaster response, although not claiming to be representative or exhaustive, demonstrate that initial commonalities among organizations and EU member states could be identified. Interestingly, aspects facilitating or constraining collaborative response were not differentiated according to functions such as situation assessment or command and control but rather related to general framework conditions. These aspects detailed above can be a starting point for further analysis. At the same time, several factors were mentioned almost consistently by the respondents and suggest that similar challenges can also be identified in countries and organizations not included in our analysis. Among them is the lack of electronic information sharing tools as well as the lack of collaboration frameworks detailing roles and responsibilities in interorganizational response settings. Continuing research on this topic by adding more in-depth research on the identified issues, and by extending the scope to further organizations and states, will enable the development of concrete suggestions for enhancing interorganizational response settings.

Acknowledgements This research has been part of the IN-PREP project on developing an integrated next generation preparedness program for improving effective interorganizational response capacity in complex environments of disasters and causes of crises. It has received funding from Horizon 2020, the European Union's Programme for Research and Innovation under grant agreement No. 740627.

Open Access This article is licensed under a Creative Commons Attribution 4.0 International License, which permits use, sharing, adaptation, distribution and reproduction in any medium or format, as long as you give appropriate credit to the original author(s) and the source, provide a link to the Creative Commons licence, and indicate if changes were made. The images or other third party material in this article are included in the article's Creative Commons licence, unless indicated otherwise in a credit line to the material. If material is not included in the article's Creative Commons licence and your intended use is not permitted by statutory regulation or exceeds the permitted use, you will need to obtain permission directly from the copyright holder. To view a copy of this licence, visit http://creativecommons. org/licenses/by/4.0/.

\section{References}

Ansell, C., and A. Boin. 2019. Taming deep uncertainty: The potential of pragmatist principles for understanding and improving strategic crisis management. Administration \& Society 51(7): 1079 .

Balcik, B., and B.M. Beamon. 2008. Facility location in humanitarian relief. International Journal of Logistics Research and Applications 11(2): 101.

Beighley, M., and A.C. Hyde. 2018. Portugal wildfire management in a new era: Assessing fire risks, resources and reforms. Independent Report. https://www.isa.ulisboa.pt/files/cef/pub/
articles/2018-04/2018_Portugal_Wildfire_Management_in_a_ New_Era_Engish.pdf. Accessed 3 Feb 2020.

BMI (Bundesministerium des Innern/Federal Ministry of the Interior). 2015. System of crisis management in Germany (System des Krisenmanagements in Deutschland). https://www.bmi.bund.de/ SharedDocs/downloads/DE/publikationen/themen/bevoelker ungsschutz/krisenmanagement-in-deutschland.pdf?_blob=publi cationFile\&v=1. Accessed 30 Jun 2019 (in German).

Boersma, K., P. Wagenaar, and J. Wolbers. 2012. Negotiating the 'trading zone'. Creating a shared information infrastructure in the Dutch public safety sector. Journal of Homeland Security and Emergency Management 9(2): Article 785.

Boin, A. 2019. The transboundary crisis: Why we are unprepared and the road ahead. Journal of Contingencies and Crisis Management 27(1): 94.

Boin, A., and F. Bynander. 2015. Explaining success and failure in crisis coordination. Geografiska Annaler: Series A, Physical Geography 97(1): 123.

Boin, A., M. Rhinard, and M. Ekengren. 2014. Managing transboundary crises. The emergence of European Union capacity. Journal of Contingencies and Crisis Management 22(3): 131.

Boin, A., P. 't Hart, E. Stern, and B. Sundelius. 2017. The politics of crisis management: Public leadership under pressure, 2nd edn. Cambridge: Cambridge University Press.

Chief Fire Officers Association, Association of Ambulance Chief Executives, and National Police Chiefs' Council. 2016. Joint doctrine: The interoperability framework. UK: JESIP (Joint Emergency Services Interoperability Principles). https://www. jesip.org.uk/uploads/media/pdf/Joint\%20Doctrine/JESIP_Joint_ Doctrine_Document.pdf. Accessed 3 May 2019.

COMM/DG/UNIT. 2018. The largest EU civil protection operation helps Sweden fight forest fires-European Civil Protection and Humanitarian Aid Operations-European Commission. https:// ec.europa.eu/echo/news/largest-eu-civil-protection-operationhelps-sweden-fight-forest-fires_en. Accessed 10 Jan 2020.

COMM/DG/UNIT. 2019. Report: More countries than ever hit by forest fires. https://ec.europa.eu/commission/presscorner/detail/ en/IP_19_6176. Accessed 10 Jan 2020.

Constantinides, P. 2013. The failure of foresight in crisis management: A secondary analysis of the Mari disaster. Technological Forecasting and Social Change 80(9): 1657.

Dutch Ministry of Security and Justice. 2013. Safety Regions Act. https://www.government.nl/binaries/government/documents/ decrees/2010/12/17/dutch-security-regions-act-part-i/safetyregions-act.pdf. Accessed 28 Apr 2019.

EC-DG ECHO (European Commission-Directorate-General for European Civil Protection and Humanitarian Aid Operations). 2017. Interim evaluation of the union civil protection mechanism, 2014-2016: Final report. https://ec.europa.eu/echo/sites/ echo-site/files/ucpm_final_report.pdf. Accessed 16 Apr 2019.

EC-DG ECHO (European Commission-Directorate-General for European Civil Protection and Humanitarian Aid Operations). 2019a. ERCC: DG ECHO daily map 9/4/2019. https://erccpor tal.jrc.ec.europa.eu/Maps/Daily-maps\#. 18.004.2019. Accessed 31 Jan 2020.

EC-DG ECHO (European Commission-Directorate-General for European Civil Protection and Humanitarian Aid Operations). 2019b. Experts training and exchange. https://ec.europa.eu/echo/ what/civil-protection/experts-training-and-exchange_en. Accessed 20 Apr 2019.

Endsley, M.R. 1995. Toward a theory of situation awareness in dynamic systems. Human Factors: The Journal of the Human Factors and Ergonomics Society 37(1): 32-64.

European Commission. 2010. Risk assessment and mapping guidelines for disaster management. $\operatorname{SEC}(2010) 1626$ final. https://ec. 
europa.eu/echo/files/about/COMM_PDF_SEC_2010_1626_F_ staff_working_document_en.pdf. Accessed 3 Feb 2020.

European Commission. 2015. Risk management capability assessment guidelines. 2015/C 261/03 (C 261/5). https://eur-lex. europa.eu/legal-content/EN/TXT/?uri=CELEX\% 3A52015XC0808\%2801\%29. Accessed 3 Feb 2020.

Flick, U. 2004. Design and process in qualitative research. In $A$ companion to qualitative research, ed. U. Flick, E. von Kardorff, and I. Steinke, 146-152. London: Sage Publications.

Flick, U. 2007. Designing qualitative research. London: Sage Publications.

Groenendaal, J., I. Helsloot, and A. Scholtens. 2013. A critical examination of the assumptions regarding centralized coordination in large-scale emergency situations. Journal of Homeland Security and Emergency Management 10(1): 113-135.

Mayring, P. 2007. On generalization in qualitatively oriented research. Forum Qualitative Social Research 8(3): Article 26.

Mayring, P. 2014. Qualitative content analysis. Theoretical foundation, basic procedures and software solution. https://nbnresolving.org/urn:nbn:de:0168-ssoar-395173. Accessed 29 Jan 2020.

National Steering Group Ireland. 2017. A framework for major emergency management. http://mem.ie/. Accessed 18 Mar 2019.

Quarantelli, E.L. 1988. Disaster crisis management: A summary of research findings. Journal of Management Studies 25(4): 373-385.

Radisch, J., C. Wendling, and S. Jaconzone. 2013. OECD working papers on public governance: The use of social media in risk and crisis communication. https://www.oecd-ilibrary.org/govern ance/the-use-of-social-media-in-risk-and-crisis-communication 5k3v01fskp9s-en. Accessed 3 Feb 2020.
Robinson, O. 2014. Sampling in interview-based qualitative research: A theoretical and practical guide. Qualitative Research in Psychology 11(1): 25-41.

Rosenthal, U., M.T. Charles, and P. 't Hart. 1989. Coping with crisis: The management of disasters, riots and terrorism. Springfield: Charles C. Thomas Publisher.

Sapountzaki, K., S. Wanczura, G. Casertano, S. Greiving, G. Xanthopoulos, and F.F. Ferrara. 2011. Disconnected policies and actors and the missing role of spatial planning throughout the risk management cycle. Natural Hazards 59(3): 1445-1474.

Stolk, D.J., R. Beerens, T. de Groeve, B. Hap, M. Kudrlova, D. Kyriazanos, M. Langinvainio, M. van der Lee, et al. 2012. ACRIMAS-D 5.1 approaches and solutions. https://www. acrimas.eu/attachments/article/5/D5-1_ACRIMAS_report_ Approaches_Solutions.pdf. Accessed 12 Apr 2019.

Turco, M., S. Jerez, S. Augusto, P. Tarín-Carrasco, N. Ratola, P. Jiménez-Guerrero, and R.M. Trigo. 2019. Climate drivers of the 2017 devastating fires in Portugal. Scientific Reports 9(1): Article 13886.

UNISDR (United Nations International Strategy for Disaster Reduction). 2009. UNISDR terminology on disaster risk reduction. Geneva: UNISDR.

UNISDR (United Nations International Strategy for Disaster Reduction). 2018. Words into action. Man-made and technological hazards. https://www.undrr.org/publication/words-action-guide line-man-made/technological-hazards. Accessed 29 Jan 2020.

Waring, S., L. Alison, G. Carter, C. Barrett-Pink, M. Humann, L. Swan, and T. Zilinsky. 2018. Information sharing in interteam responses to disaster. Journal of Occupational and Organizational Psychology 91(3): 591-619.

Wybo, J.-L., and K.M. Kowalski. 1998. Command centers and emergency management support. Safety Science 30(1-2): $131-138$. 